Published in final edited form as:

Transl Res. 2017 May 31; 184: 12-20.e1. doi:10.1016/j.trsl.2017.01.003.

\title{
Procoagulant extracellular vesicles in amniotic fluid
}

\author{
Lena Hell ${ }^{\ddagger}$, Lukas Wisgrill $\uparrow$, Cihan Ay $\ddagger$, Andreas Spittler§, Michael Schwameis ${ }^{\dagger}$, Bernd $^{\S}$ \\ Jilma $^{\dagger}$, Ingrid Pabinger ${ }^{\ddagger}$, Peter Altevogt ${ }^{\text {TII}}$, and Johannes Thaler ${ }^{\ddagger}$ \\ ${ }^{\ddagger}$ Clinical Division of Haematology and Haemostaseology, Department of Medicine I, Medical \\ University of Vienna, Austria
}

"Clinical Division of Neonatology, Paediatric Intensive Care \& Neuropaediatrics, Department of Paediatrics and Adolescent Medicine, Medical University of Vienna

§Department of Surgery, Medical University of Vienna

१ीTumor Immunology Programme, German Cancer Research Center

tDepartment of Clinical Pharmacology, Medical University of Vienna

\section{Summary}

Embolization of amniotic fluid (AF) into the blood circulation leads to disseminated intravascular coagulation (DIC). Procoagulant phosphatidylserine (PS)- and tissue factor (TF) exposing extracellular vesicles (EVs) might play an important role in AF embolism induced DIC. It was the aim of the present study to perform analyses of the procoagulant properties of AF with a panel of functional coagulation assays and flow cytometry. We applied a prothrombinase assay (that quantifies PS exposure on EVs), an EV-associated TF activity assay, a fibrin generation assay, a thrombin generation assay, a whole blood clotting model and flow cytometry in AF and control plasma. We found that PS exposure on EVs was 21-fold increased in AF compared to plasma. Also EV-associated TF activity was highly increased in AF compared to plasma. AF derived EVs activated the blood coagulation cascade via PS and TF in the fibrin- and thrombin generation assay. In a whole blood clotting model AF derived EVs significantly shortened the clotting time from $734 \pm 139$ seconds in the presence- to $232 \pm 139$ seconds in the absence of an anti-TF antibody. The contact activation pathway via factor FXII was not affected. Applying flow cytometry, a sub-population of $\mathrm{PS}^{+}$and $\mathrm{TF}^{+} \mathrm{EVs}$ was identified in $\mathrm{AF}$ but not in control plasma. In conclusion, we investigated the effect of $\mathrm{AF}$ on blood coagulation and found that $\mathrm{PS}^{+}$and $\mathrm{TF}^{+}$

Correspondence: Dr. Johannes Thaler, PhD, Clinical Division of Haematology and Haemostaseology, Department of Medicine I, Medical University of Vienna, Waehringer Guertel 18-20, A-1090 Vienna, Austria, Phone number: +43 140400 27570, Fax number: +43140400 4030, johannes.thaler@meduniwien.ac.at.

\section{Addendum}

Contribution: J. Thaler, L. Hell, I. Pabinger, and C. Ay were responsible for study concept and design; L. Hell, J. Thaler, L. Wisgrill, and P. Altevogt acquired the data; L. Hell, J. Thaler, L. Wisgrill, C. Ay, M. Schwameis, B. Jilma, I. Pabinger, P. Altevogt, and A. Spittler analyzed and interpreted the data; J. Thaler and L. Hell drafted the manuscript; L. Hell, J. Thaler, L. Wisgrill, C. Ay, M. Schwameis, B. Jilma, I. Pabinger, P. Altevogt, and A. Spittler critically reviewed the manuscript for important intellectual content; I. Pabinger, C. Ay, and B. Jilma obtained funding; J. Thaler and L. Wisgrill provided statistical analysis; L. Hell, J. Thaler, L. Wisgrill, C. Ay, M. Schwameis, B. Jilma, I. Pabinger, P. Altevogt, and A. Spittler provided administrative, technical, or material support; J. Thaler was the study supervisor; all authors took part in reviewing and editing the entire manuscript and approved the final version of the manuscript.

Disclosure of Conflict of Interests

The authors declare no competing financial interests. 
EVs determine its procoagulant potential. Taken together our data further delineate the pathomechanisms underlying AF induced coagulopathy.

\section{Introduction}

Amniotic fluid (AF) embolism syndrome is a life threatening condition that may occur during pregnancy or shortly after delivery. It is characterised by the triad of disseminated intravascular coagulation (DIC), hypoxia and hypotension. The estimated incidence of AF embolism is low ( 1 to 12 cases per 100,000 deliveries) but reported case fatality rates are ranging from $20 \%$ to $61 \%[1,2]$.

A central role in the pathogenesis of AF embolism-associated DIC was suggested for AFderived procoagulant extracellular vesicles (EVs), which were also referred to as microparticles or microvesicles [3-5]. Such procoagulant EVs have a phosphatidylserine (PS)-rich surface that binds coagulation factors and facilitates the formation of tenase- and prothrombinase complexes, which induce thrombin- and fibrin generation [6, 7]. Also a highly procoagulant EV sub-population was detected in AF that expresses tissue factor (TF) in addition to PS on the surface [3]. Tissue factor is a membrane-associated glycoprotein which functions as the initiator of the blood coagulation cascade by forming a complex with activated blood coagulation factor VII (FVIIa) [8]. Such $\mathrm{TF}^{+}$EVs are not detectable in the blood of healthy individuals [9] but elevated levels are found in patients with prothrombotic conditions like advanced malignancy and sepsis [10-14].

It remains to be investigated how the blood coagulation cascade gets activated upon contact with AF. Also whether EVs and particularly the highly procoagulant sub-population of $\mathrm{TF}^{+}$ EVs play an important role in AF embolism-associated DIC has not been elucidated yet. A better knowledge of the procoagulant properties of $\mathrm{AF}$ is a prerequisite for the development of improved diagnostic- and treatment modalities. Therefore, it was the aim of the present study to perform analyses of the procoagulant properties of $\mathrm{AF}$ with a panel of quantitativeand functional coagulation assays.

\section{Material and methods}

\section{Collection of amniotic fluid}

Human AF was collected at the University of Heidelberg for routine amniocentesis in healthy women $\geq 38$ years of age with normal pregnancies between the $15^{\text {th }}$ and $18^{\text {th }}$ week of gestation $(n=10)$ for detection of fetal chromosomal disorders. Samples were stored at $-80^{\circ} \mathrm{C}$ after removal of cells by centrifugation at $250 \mathrm{~g}$ for 5 minutes until measurements were performed in series. Detailed clinical data was not collected due to a restricted approval of the ethics committee of the University of Heidelberg.

\section{Collection of blood}

Blood was collected from healthy individuals and cancer patients with overt DIC for the comparison of the procoagulant properties of AF to plasma. Healthy individuals (7 females) were free of acute or chronic disease and were not taking any medication. Cancer patients 
(10 females) had overt DIC according to the score of the International Society on Thrombosis and Haemostasis [15]. Clinical characteristics of healthy individuals and DIC patients are given in Supplementary Table 1. The collection of blood samples and documentation of clinical characteristics were approved by the Ethics Committee of the Medical University of Vienna. Blood was drawn from the antecubital vein with a 21- gauge butterfly needle without tourniquet. Samples from cancer patients $(n=10)$ and healthy individuals ( $\mathrm{n}=7$ ) were collected into $3,2 \%$ sodium citrate, immediately centrifuged at $3000 \mathrm{~g}$ for 10 minutes. Platelet poor plasma aliquots from cancer patients and healthy controls were stored at $-80^{\circ} \mathrm{C}$ until measurements were performed in series.

\section{Preparation of amniotic fluid and plasma}

AF- and plasma samples were thawed in a water bath at $37{ }^{\circ} \mathrm{C}$ for 5 minutes immediately before measurements were performed. In some thrombin generation- and fibrin generation experiments AF was used that was filtered through a membrane with $0.1 \mu \mathrm{m}$ pore size (Merck Millipore Ltd., Tullagreen, Carrigtwohill, Co. Cork, IRL.) for depletion of larger EVs as described previously [16].

\section{Flow cytometry}

For immunolabeling, $\mathrm{AF}$ and platelet poor plasma were thawed in a water bath at $37^{\circ} \mathrm{C}$ and were immediately processed as described elsewhere [17, 18]. First, $20 \mu \mathrm{l}$ sample was diluted in $40 \mu \mathrm{l}$ PBS and stained with $2 \mu \mathrm{l} \mathrm{FITC-labeled} \mathrm{anti-} \mathrm{TF} \mathrm{(clone} \mathrm{TF9-10H10,} \mathrm{LSbio,} \mathrm{Seattle,}$ WA, USA) for 2 hours in the dark at room temperature (RT). In a second step, 2,5 $\mu$ l Cy5labeled annexin V (Biovision, Milpitas, CA, USA) was added to the sample and diluted with calcium binding buffer, resulting in a total volume of $500 \mu \mathrm{l}$, and incubated for 1 hour in the dark at RT. Two ATU/ml recombinant Hirudin (Sigma Aldrich, St. Louis, MO, USA) was added to the calcium binding buffer to prevent clot formation. Diluted binding buffer was sterile filtered through a $0.2 \mu \mathrm{m}$ mesh to reduce background noise. Prior to staining, the antibody mixture was centrifuged at $20.000 \mathrm{x}$ g for 30 minutes to remove fluorescent particles as described elsewhere [18]. $\mathrm{TF}^{+} \mathrm{EV}$ events were defined as double positive for annexin $\mathrm{V}$ and $\mathrm{TF}$.

Flow cytometry was performed using a CytoFLEX S flow cytometer (Beckman Coulter, Krefeld, GER). The fluorescence signal from Cy5 $\left(\lambda_{e x^{*}}=635 \mathrm{~nm} ; \lambda_{e m}=660 \pm 10 \mathrm{~nm}\right)$ was used to trigger detection of AnnV-Cy5 ${ }^{+}$EVs. For calibration of the violet side scatter (405 $\mathrm{nm}$ ), fluorescent silica beads (1000 nm) were additionally used to define a EV gate based on the scatter properties. Enumeration of EVs was performed using volumetric measurement of the CytoFLEX (events/ $\mu$ ).

\section{Extracellular vesicle-associated prothrombinase activity in amniotic fluid}

Levels of PS exposure on EVs were measured using a commercially available prothrombinase assay (Zymuphen MP-activity kit, Hyphen BioMed, Andresy, France). In this functional assay EVs were captured by annexin V. Phosphatidylserine exposure on EVs was detected through its ability to promote the conversion from prothrombin to thrombin by factor $\mathrm{Xa}$ in the presence of $\mathrm{FVa}$ and $\mathrm{CaCl}_{2}$. Substrates were present in excess to ensure that PS exposure on EVs was the rate limiting parameter of the reaction. A chromogenic 
substrate for thrombin was used and the absorbance changes were converted into levels of PS exposure on EVs (expressed as PS equivalent) by reference to a standard curve constructed by using phospholipids of defined composition. Each measurement was performed in duplicates.

\section{Extracellular vesicle-associated tissue factor activity in amniotic fluid}

The measurement of EV-associated TF activity was performed as previously described [19]. Briefly, after preparation, EVs were incubated with either an antibody for human TF (hTF1, $500 \mu \mathrm{g} / \mathrm{ml}, 1 \mu \mathrm{l}$; BD Biosciences, San Jose, CA, USA) or a control antibody (mouse IgG: 4 $\mu \mathrm{g} / \mathrm{ml} ; 1 \mu \mathrm{l}$; Sigma-Aldrich, St. Louis, $150 \mathrm{USA}$ ) and then $50 \mu \mathrm{l}$ aliquots were added to duplicate wells of a 96-well plate. In the next step, $50 \mu \mathrm{l}$ of HBSA containing $10 \mathrm{nM}$ factor VIIa (FVIIa), $300 \mathrm{nM}$ factor X (FX) and $10 \mathrm{mM} \mathrm{CaCl}_{2}$ were added to each sample and the mixture incubated for $2 \mathrm{~h}$ at $37^{\circ} \mathrm{C}$. FXa generation was stopped by the addition of $25 \mu \mathrm{l}$ of EDTA buffer and $25 \mu \mathrm{l}$ of the chromogenic substrate Pefachrome FXa 8595 (4 mM; Pentapharm, Basel, Switzerland) were added and incubated at $37{ }^{\circ} \mathrm{C}$ for $15 \mathrm{~min}$. Finally, absorbance at $405 \mathrm{~nm}$ was measured using a Multiscan Spectrum microplate reader (Thermo Scientific Inc., Bremen, Germany). EV-associated TF activity was calculated by reference to a standard curve that was generated using relipidated recombinant human TF. The TFdependent FXa generation (pg/ml), which represents the EV-associated TF activity, was determined by subtracting the amount of FXa generated in the presence of hTF1 from the amount of FXa generated in the presence of the control antibody. Each measurement was performed in duplicates.

\section{Amniotic fluid induced thrombin generation}

Thrombin generation was measured after addition of $\mathrm{AF}(10 \mu \mathrm{l})$, either unfiltered or filtered (0.1 $\mu \mathrm{m}$ membrane), to vesicle-depleted normal pooled plasma (NPP; 1 hour at $150000 \mathrm{~g} ; 40$ $\mu \mathrm{l})$. Thrombin generation was initiated by addition of $\mathrm{CaCl}_{2}(15 \mathrm{mM}, 50 \mu \mathrm{l})$ and monitored with the fluorigenic substrate Z-Gly-Gly-Arf AMC (Bachem, Bubendorf, Switzerland) with a FLx800 microlate reader (BioTek, Winooski, USA). Each measurement was performed in duplicates after pre-incubation of $\mathrm{AF}$ for 15 minutes at $37^{\circ} \mathrm{C}$ with either a control antibody (mouse $\mathrm{IgG}, 1 \mu \mathrm{L}$ ), or an anti-TF antibody (hTF1, $1 \mu \mathrm{l})$, or an anti-factor XII antibody (1 $\mu \mathrm{g} / \mathrm{ml}, 1 \mu \mathrm{l}$, Sanguine, Amsterdam, The Netherlands), or annexin V ( $25 \mu \mathrm{g} / \mathrm{ml}, 1 \mu \mathrm{l}$, Sigma Aldrich, St. Louis, MO, USA).

\section{Amniotic fluid induced fibrin generation}

Fibrin generation was measured after addition of $\mathrm{AF}(10 \mu \mathrm{l})$, either unfiltered or filtered $(0.1$ $\mu \mathrm{m}$ membrane), to vesicle-depleted NPP $(60 \mu \mathrm{l})$. Fibrin clot generation was initiated by addition of $\mathrm{CaCl}_{2}(20 \mathrm{mM}, 20 \mu \mathrm{l})$. The lag phase of the turbidity curve, reflecting the time until the onset of clot formation, was recorded with a Multiscan Spectrum microplate reader (Thermo Scientific Inc., Bremen, Germany) at a wavelength of $405 \mathrm{~nm}$. Each measurement was performed in duplicates after pre-incubation of AF for 15 minutes at $37{ }^{\circ} \mathrm{C}$ with either a control antibody (mouse IgG, $4 \mu \mathrm{g} / \mathrm{mL} ; 1 \mu \mathrm{L}$ ) or an anti-TF antibody (hTF1, $1 \mu \mathrm{l}$ ), or an antifactor XII $(1 \mu \mathrm{l})$, or annexin V $(1 \mu \mathrm{l})$. 


\section{Amniotic fluid induced whole blood clotting}

Rotation thromboelastometry (ROTEM ${ }^{\circledR}$, Pentapharm, Munich, Germany) was used to investigate the effect of $\mathrm{AF}$ and $\mathrm{AF}$ derived $\mathrm{EV}$ s on clot formation of whole blood. Thrombolastometry with the ROTEM ${ }^{\circledR}$ Coagulation Analyzer was described in detail previously [20]. Briefly, whole blood samples from 3 young and healthy female donors were collected into 3.8\% sodium citrate tubes. Thromboelastometry measurements were performed within 1 hour after blood storage at room temperature. AF fluid or AF derived EVs, which were pelleted from cell free AF by high speed centrifugation $(18.000 \mathrm{~g}$ for 20 minutes) and re-suspended in buffer were incubated for 15 minutes with either a control IgG antibody or the HTF1 antibody or a FXII antibody. Just before running the assay, AF or AF derived EVs $(10 \mu \mathrm{l})$, were added to whole blood $(400 \mu \mathrm{l})$. In the next step, blood clotting was initiated by addition of $20 \mu \mathrm{l}$ of $\mathrm{CaCl}_{2}(0.2 \mathrm{M})$.

\section{Statistics}

Continuous variables were described by the mean values \pm standard deviation (SD). Categorical variables were described by the absolute numbers and percentages. Data were analyzed by 2 -tailed Student $t$ test. The correlation between continuous variables was assessed by Pearson's rank correlation coefficient. Two-sided p-values smaller than 0.05 were considered as indicating statistical significance. Statistical analyses were performed with SPSS Version 17.0.2.

\section{Results}

\section{Flow cytometry}

Applying flow cytometry significantly higher $\mathrm{PS}^{+} \mathrm{EV}$ levels were detected in AF samples compared to plasma of health controls (291693 \pm 103217 vs. $1909 \pm 578$ events $/ \mu$; $p<0.001)$. Furthermore, we found that a high proportion of detected $\mathrm{PS}^{+} \mathrm{EVs}$ in $\mathrm{AF}$ also exposed TF (21706 \pm 9373 events/ $\mu \mathrm{l})$. We did not detect $\mathrm{TF}^{+} \mathrm{EVs}$ in plasma (Figure 1A-1C).

\section{Extracellular vesicle-associated prothrombinase activity is highly elevated in amniotic fluid}

Mean EV-associated prothrombinase activity was $33.3 \pm 19.4$ (nanomolar phosphatidylserine equivalent [nM PS]) in AF and $1.6 \pm 0.4 \mathrm{nM}$ PS $(p<0.001)$ in plasma from healthy controls (Figure 2A).

\section{Extracellular vesicle-associated tissue factor activity is highly elevated in amniotic fluid}

Mean EV-associated TF activity was $69.11 \pm 9.85 \mathrm{pg} / \mathrm{mL}$ in AF. In the plasma of healthy individuals EV-associated TF activity was $0.04 \pm 0.10 \mathrm{pg} / \mathrm{ml}$, which was clearly below the lower detection limit of the applied assay (about $0.5 \mathrm{pg} / \mathrm{mL} ; p<0.001$ ) [21]. To have a better estimate of the extend of elevation of $\mathrm{EV}$-associated TF activity in $\mathrm{AF}$, measurements were also performed in the plasma of 10 cancer patients with overt DIC, in whom highly elevated EV-associated TF activity was previously described [22-24]. Compared to DIC patients, who had a mean EV-associated TF activity of $7.35 \pm 2.58 \mathrm{pg} / \mathrm{ml}$, EV-associated TF activity in AF was 9.4-fold increased ( $p<0.001$; Figure 2B). 


\section{Amniotic fluid induced thrombin generation depends on tissue factor- and phosphatidylserine exposing extracellular vesicles}

When vesicle-depleted NPP was just recalcified no thrombin generation (TG) was detected. Addition of unfiltered AF to vesicle-depleted NPP induced a peak TG of $120 \pm 28 \mathrm{nM}$ after a lag phase of $507 \pm 75 \mathrm{~s}$. When AF was pre-incubated with an anti-TF antibody and added to recalcified NPP peak TG was reduced to $80 \pm 27 \mathrm{nM}(p<0.001)$ and the lag phase was prolonged to $783 \pm 158 \mathrm{~s}, p<0.001$ ). Filtering AF through a $0.1 \mu \mathrm{m}$ membrane for depletion of larger EVs reduced peak thrombin generation to $60 \pm 18 \mathrm{nM}$ and prolonged the lag phase to $852 \pm 115 \mathrm{~s}(p<0.001)$. Addition of anti-TF antibody to filtered AF further reduced thrombin generation to $42 \pm 13 \mathrm{nM}$ and prolonged the lag phase to $1143 \pm 157 \mathrm{~s}(p<0.001)$. When AF was pre-incubated with annexin V (which blocked PS on the surface of EVs) no TG occurred, proving the dependence of TG on PS. Pre-incubation of AF with an anti-FXII antibody had no effect on peak TG $(p=0.631)$ and TG lag phase $(p=0.410)$. Mean peak TG values \pm SD are illustrated in Figure $3 \mathrm{~A}$ and representative thrombin generation curves are given in Figure 3C.

\section{Amniotic fluid induced fibrin generation depends on tissue factor- and phosphatidylserine exposing extracellular vesicles}

Vesicle-depleted NPP did not clot when it was just recalcified for the measurement time of $4000 \mathrm{~s}$. Addition of AF to vesicle-depleted NPP induced clotting after $305 \pm 42 \mathrm{~s}$. Clotting was significantly prolonged by addition of AF that was pre-incubated with an anti-TF antibody to $407 \pm 99 \mathrm{~s}(p=0.001)$. Clotting was prolonged to $464 \pm 60 \mathrm{~s}$ when AF was filtered through a $0.1 \mu \mathrm{m}$ membrane for depletion of larger EVs $(p<0.001)$. Clotting was further prolonged to $650 \pm 114 \mathrm{~s}$ when $\mathrm{AF}$ was pre-incubated with an anti-TF antibody and filtered through a $0.1 \mu \mathrm{m}$ membrane $(p<0.001)$. Clot formation was abolished when AF was pre-incubated with annexin V. Pre-incubation of AF with an anti-FXII antibody had no effect on the plasma clotting time $(p=0.410$ ). After plasma was fully clotted no signs of fibrinolysis were found by semiquantitative interpretation of fibrin generation curves. Mean clotting time values \pm SD are illustrated in Figure 3B.

\section{The procoagulant activity of amniotic fluid depends on TF-exposing extracellular vesicles in a whole blood clotting model}

To investigate whether AF-derived EVs are the true source of coagulation activation following AF embolism, we used a whole blood clotting model (ROTEM thromboelastometry). Whole blood ( $\mathrm{n}=3$ healthy female donors) that was just recalcified clotted after $656 \pm 35 \mathrm{~s}$. Addition of pooled AF dramatically shortened the clotting time of blood to $182 \pm 44 \mathrm{~s}$ ( $p<0.001$; Figure $4 \mathrm{~A}$ shows representative curves). Next EVs from AF were pelleted by high-speed centrifugation, washed, re-suspended in buffer, and pooled. Addition of these pooled AF-derived EVs shortened the whole blood clotting time to 232 $\pm 29 \mathrm{~s}(p<0.001)$. Pre-incubation of AF-derived EVs with an anti-TF antibody resulted in a strong prolongation of the clotting time of blood to $734 \pm 139 \mathrm{~s}(p<0.001)$. Finally, we compared the procoagulant activity of AF and AF-derived EVs with that of a snake venom from Bothrops atrox, referred to as reptilase, which activates the final steps of the coagulation cascade by directly converting fibrinogen into fibrin. AF had a stronger effect on 
the blood clotting time than reptilase, which was added in excess ( $0.2 \mathrm{BU}: \mathrm{p}=0.032$; and 0.4 BU: $p<0.001$; Figure 4B). After whole blood was fully clotted no signs of fibrinolysis were found by semiquantitative interpretation of rotational thromboelastometry curves.

\section{Correlations between assays}

Pearson correlation coefficients between selected parameters of the EV-associated prothrombinase activity assay, EV-associated TF activity assay, thrombin generation assay, fibrin generation assay and flow cytometry are given in Table 1. The strongest correlations were found between the thrombin generation assay lag phase and fibrin generation lag phase $(\mathrm{r}=0.875)$, and peak thrombin generation and $\mathrm{EV}$-associated prothrombinase activity $(\mathrm{r}=0.804)$.

\section{Discussion}

In the present study we applied a panel of assays (including an EV-associated prothrombinase assay, an EV-associated tissue factor activity assay, a thrombin generation assay, a fibrin generation assay, a whole blood clotting model and flow cytometry) to quantify the procoagulant properties of AF. Using different antibodies and annexin $\mathrm{V}$ in the presence and absence of a membrane filter in different assays we found that AF derived EVs activated the blood coagulation cascade in a PS, TF, and size-dependent manner. Applying flow cytometry we could identify a sub-population of PS and TF exposing EVs that was absent from the circulation of healthy controls.

The use of recombinant FVIIa has been advocated for the treatment of patients with AF embolism-associated DIC [2, 25, 26]. Applying the EV-associated TF activity assay, we found that co-incubation of AF derived EVs with recombinant FVIIa leads to exceedingly high FXa generation. Therefore, our data indicates that therapeutic administration of recombinant FVIIa could expose patients with AF embolism-associated DIC to an unacceptable high risk of developing venous- or arterial thromboembolism. Consistently, Leigthon and colleagues found in a pooled analysis that the majority of patients with $\mathrm{AF}$ embolism associated DIC who received FVIIa died or suffered permanent damage (14/16 patients) due to complications like multiple organ failure, pulmonary hypertension, stroke and renal failure that were most probably caused by organ thrombosis [27]. In contrast, fewer patients died or had permanent disabilities, when they did not receive FVIIa.

Applying a fibrin generation assay and whole blood thromboelastometry we found no in vitro evidence for an effect of $\mathrm{AF}$ on fibrinolysis. This is consistent with two previous studies [28, 29]. Moreover, low concentrations of the components of the fibrinolytic system (only fractions of the respective values in the maternal plasma) were identified in AF [30]. It is therefore likely that hyperfibrinolysis following AF embolism is secondary to initial EVTF induced activation of the coagulation system [31].

Amniotic fluid is largely made up of fetal urine but also consists of nasal-, tracheal-, and pulmonary fluids [32]. Previously, procoagulant $\mathrm{TF}^{+} \mathrm{EVs}$ were found in the urine and saliva of healthy individuals [33], which therefore might also be the source of $\mathrm{TF}^{+} \mathrm{EV}$ s in $\mathrm{AF}$. Higushi and colleagues studied fetal lung surfactant in AF and found that its thromboplastic 
activity depends on the surfactant-derived lipoprotein content in AF [34]. Analogously, we detected a strong correlation between the expression of the phospholipid phosphatidylserine on EVs and the thromboplastic activity of EVs in AF. Moreover, about 30 years ago a cysteine protease that directly activated FX in the absence of FVII was detected in AF [35]. Our results do not confirm these findings as only little generation of activated FX was detectable in EV-depleted AF in the absence of FVII in our present study (data not shown).

The lack of detailed clinical data from the pregnant women of whom we obtained AF is a limitation of the present study, which was due to a restricted approval of the institutional ethics committee. However, only women who had a routine amniocentesis, were healthy, and had a normal pregnancy were included. Therefore, the investigated AF samples can be regarded as physiological and representative.

For the comparison of the procoagulant properties of AF to plasma we also collected blood from healthy controls and cancer patients with DIC. It needs to be mentioned that there was a significant age difference between the subjects who had amniotic fluid collected and those who had blood collected. Healthy controls were significantly younger and cancer patients with DIC significantly older.

Correlation coefficients between AF induced prothrombinase-, fibrin-, and thrombin generation were high and ranged between 0.62 and 0.88 . No correlations were found between these assays and the EV-associated TF activity assay. This might be due to the measurement of factor Xa generation outside the plasma milieu and due to specific characteristics of recombinant activated factor VII, which was used in this assay. Between $\mathrm{PS}^{+} / \mathrm{TF}^{+} \mathrm{EVs}$ determined by flow cytometry and the other assays we found only one significant correlation. $\mathrm{PS}^{+} / \mathrm{TF}^{+}$EVs correlated positively with the fibrin generation lag phase. This was contradictory to the other results as a negative correlation with the fibrin generation lag phase (and therefore a shortening of the clotting time) would be expected Quantification of EVs by flow cytometry has well-described inherent drawbacks that are likely to account for this counter-intuitive result, being the most important one the inaccurate detection of EVs below a size of about 0.2 to $0.3 \mu \mathrm{m}$ [36]. Also due to these limitations we did not investigate the cellular origin of EVs in AF with flow cytometry and decided to focus on the procoagulant aspects of EVs. However, we used a well-established flow cytometry protocol for the measurement of TF-bearing EVs [17] and we could identify a subpopulation of PS and TF exposing EVs in AF, which was absent from the plasma of healthy controls.

In conclusion, we investigated the effect of $\mathrm{AF}$ on blood coagulation and found that $\mathrm{PS}^{+}$and $\mathrm{TF}^{+}$EVs determine its procoagulant potential. In the EV-associated TF activity assay coincubation of $\mathrm{AF}$ derived $\mathrm{TF}^{+} \mathrm{EVs}$ with recombinant FVIIa generated extremely high amounts of FXa cautioning against the use of recombinant FVIIa in patients with AF embolism. Taken together our data further delineate the pathomechanisms underlying AF induced coagulopathy, which could help refine treatment modalities. 


\section{Supplementary Material}

Refer to Web version on PubMed Central for supplementary material.

\section{Acknowledgments}

This study was supported by the Austrian Science Fund (FWF), Special Research Program (SFB) 5405-B21 and 5404-B21

Abbreviations
$\begin{array}{cl}\text { AF } & \text { amniotic fluid } \\ \text { EVs } & \text { extracellular vesicles } \\ \text { DIC } & \text { disseminated intravascular coagulation } \\ \text { F } & \text { factor } \\ \text { NPP } & \text { normal pooled plasma } \\ \text { PS } & \text { phosphatidylserine } \\ \text { TF } & \text { tissue factor }\end{array}$

\section{References}

[1]. Clark SL, Hankins GD, Dudley DA, Dildy GA, Porter TF. Amniotic fluid embolism: analysis of the national registry. Am J Obstet Gynecol. 1995; 172:1158-67. [PubMed: 7726251]

[2]. Conde-Agudelo A, Romero R. Amniotic fluid embolism: an evidence-based review. Am J Obstet Gynecol. 2009; 201:445 e1-13. [PubMed: 19879393]

[3]. Lockwood CJ, Bach R, Guha A, Zhou XD, Miller WA, Nemerson Y. Amniotic fluid contains tissue factor, a potent initiator of coagulation. Am J Obstet Gynecol. 1991; 165:1335-41. [PubMed: 1957857]

[4]. Uszynski W, Zekanowska E, Uszynski M, Zylinski A, Kuczynski J. New observations on procoagulant properties of amniotic fluid: microparticles (MPs) and tissue factor-bearing MPs (MPs-TF), comparison with maternal blood plasma. Thromb Res. 2013; 132:757-60. [PubMed: 24157083]

[5]. Liu S, Wei L, Zhang Y, Xu M, Wang C, Zhou J. Procoagulant activity and cellular origin of microparticles in human amniotic fluid. Thromb Res. 2014; 133:645-51. [PubMed: 24439679]

[6]. Hugel B, Martinez MC, Kunzelmann C, Freyssinet JM. Membrane microparticles: two sides of the coin. Physiology (Bethesda). 2005; 20:22-7. [PubMed: 15653836]

[7]. Gardiner C, Tannetta DS, Simms CA, Harrison P, Redman CW, Sargent IL. Syncytiotrophoblast microvesicles released from pre-eclampsia placentae exhibit increased tissue factor activity. PLoS One. 2011; 6:e26313. [PubMed: 22022598]

[8]. Mackman N. The many faces of tissue factor. J Thromb Haemost. 2009; 7(Suppl 1):136-9. [PubMed: 19630786]

[9]. Butenas S, Bouchard BA, Brummel-Ziedins KE, Parhami-Seren B, Mann KG. Tissue factor activity in whole blood. Blood. 2005; 105:2764-70. [PubMed: 15604222]

[10]. Thaler J, Ay C, Mackman N, Metz-Schimmerl S, Stift J, Kaider A, et al. Microparticle-associated tissue factor activity in patients with pancreatic cancer: correlation with clinicopathological features. Eur J Clin Invest. 2013; 43:277-85. [PubMed: 23398637] 
[11]. Nieuwland R, Berckmans RJ, McGregor S, Boing AN, Romijn FP, Westendorp RG, et al. Cellular origin and procoagulant properties of microparticles in meningococcal sepsis. Blood. 2000; 95:930-5. [PubMed: 10648405]

[12]. Hellum M, Ovstebo R, Brusletto BS, Berg JP, Brandtzaeg P, Henriksson CE. Microparticleassociated tissue factor activity correlates with plasma levels of bacterial lipopolysaccharides in meningococcal septic shock. Thromb Res. 2014; 133:507-14. [PubMed: 24423888]

[13]. Gieseler F, Luhr I, Kunze T, Mundhenke C, Maass N, Erhart T, et al. Activated coagulation factors in human malignant effusions and their contribution to cancer cell metastasis and therapy. Thromb Haemost. 2007; 97:1023-30. [PubMed: 17549306]

[14]. Soff GA. Commentary on "microparticle-associated tissue factor activity in patients with metastatic pancreatic cancer and its effect on fibrin clot formation". Transl Res. 2014; 163:13640. [PubMed: 24139900]

[15]. Levi M, Toh CH, Thachil J, Watson HG. Guidelines for the diagnosis and management of disseminated intravascular coagulation. British Committee for Standards in Haematology. Br J Haematol. 2009; 145:24-33. [PubMed: 19222477]

[16]. Gheldof D, Hardij J, Cecchet F, Chatelain B, Dogne JM, Mullier F. Thrombin generation assay and transmission electron microscopy: a useful combination to study tissue factor-bearing microvesicles. J Extracell Vesicles. 2013; 2

[17]. Arraud N, Gounou C, Turpin D, Brisson AR. Fluorescence triggering: A general strategy for enumerating and phenotyping extracellular vesicles by flow cytometry. Cytometry A. 2016; 89:184-95. [PubMed: 25857288]

[18]. Aass HC, Ovstebo R, Troseid AM, Kierulf P, Berg JP, Henriksson CE. Fluorescent particles in the antibody solution result in false TF- and CD14-positive microparticles in flow cytometric analysis. Cytometry A. 2011; 79:990-9. [PubMed: 21990118]

[19]. Khorana AA, Francis CW, Menzies KE, Wang JG, Hyrien O, Hathcock J, et al. Plasma tissue factor may be predictive of venous thromboembolism in pancreatic cancer. $\mathrm{J}$ Thromb Haemost. 2008; 6:1983-5. [PubMed: 18795992]

[20]. Spiel AO, Mayr FB, Firbas C, Quehenberger P, Jilma B. Validation of rotation thrombelastography in a model of systemic activation of fibrinolysis and coagulation in humans. J Thromb Haemost. 2006; 4:411-6. [PubMed: 16420574]

[21]. Lee RD, Barcel DA, Williams JC, Wang JG, Boles JC, Manly DA, et al. Pre-analytical and analytical variables affecting the measurement of plasma-derived microparticle tissue factor activity. Thromb Res. 2012; 129:80-5. [PubMed: 21737126]

[22]. Langer F, Spath B, Haubold K, Holstein K, Marx G, Wierecky J, et al. Tissue factor procoagulant activity of plasma microparticles in patients with cancer-associated disseminated intravascular coagulation. Ann Hematol. 2008; 87:451-7. [PubMed: 18292996]

[23]. Dicke C, Amirkhosravi A, Spath B, Jimenez-Alcazar M, Fuchs T, Davila M, et al. Tissue factordependent and -independent pathways of systemic coagulation activation in acute myeloid leukemia: a single-center cohort study. Exp Hematol Oncol. 2015; 4:22. [PubMed: 26251762]

[24]. Thaler J, Pabinger I, Sperr WR, Ay C. Clinical evidence for a link between microparticleassociated tissue factor activity and overt disseminated intravascular coagulation in patients with acute myelocytic leukemia. Thromb Res. 2014; 133:303-5. [PubMed: 24439676]

[25]. Lim Y, Loo CC, Chia V, Fun W. Recombinant factor VIIa after amniotic fluid embolism and disseminated intravascular coagulopathy. Int J Gynaecol Obstet. 2004; 87:178-9. [PubMed: 15491576]

[26]. Prosper SC, Goudge CS, Lupo VR. Recombinant factor VIIa to successfully manage disseminated intravascular coagulation from amniotic fluid embolism. Obstet Gynecol. 2007; 109:524-5. [PubMed: 17267882]

[27]. Leighton BL, Wall MH, Lockhart EM, Phillips LE, Zatta AJ. Use of recombinant factor VIIa in patients with amniotic fluid embolism: a systematic review of case reports. Anesthesiology. 2011; 115:1201-8. [PubMed: 21720243]

[28]. Harnett MJ, Hepner DL, Datta S, Kodali BS. Effect of amniotic fluid on coagulation and platelet function in pregnancy: an evaluation using thromboelastography. Anaesthesia. 2005; 60:1068-72. [PubMed: 16229690] 
[29]. Liu EH, Shailaja S, Koh SC, Lee TL. An assessment of the effects on coagulation of midtrimester and final-trimester amniotic fluid on whole blood by Thrombelastograph analysis. Anesth Analg. 2000; 90:333-6. [PubMed: 10648317]

[30]. Uszynski M, Uszynski W. Coagulation and fibrinolysis in amniotic fluid: physiology and observations on amniotic fluid embolism, preterm fetal membrane rupture, and pre-eclampsia. Semin Thromb Hemost. 2011; 37:165-74. [PubMed: 21370219]

[31]. Chapin JC, Hajjar KA. Fibrinolysis and the control of blood coagulation. Blood Rev. 2015; 29:17-24. [PubMed: 25294122]

[32]. Underwood MA, Gilbert WM, Sherman MP. Amniotic fluid: not just fetal urine anymore. J Perinatol. 2005; 25:341-8. [PubMed: 15861199]

[33]. Berckmans RJ, Sturk A, van Tienen LM, Schaap MC, Nieuwland R. Cell-derived vesicles exposing coagulant tissue factor in saliva. Blood. 2011; 117:3172-80. [PubMed: 21248061]

[34]. Higuchi M, Hirano H, Maki M. The thromboplastic activity of lung surfactant in amniotic fluid and its application to prenatal assessment of fetal lung maturity. Tohoku J Exp Med. 1981; 133:267-73. [PubMed: 6914842]

[35]. Gordon SG, Hasiba U, Cross BA, Poole MA, Falanga A. Cysteine proteinase procoagulant from amnion-chorion. Blood. 1985; 66:1261-5. [PubMed: 3933592]

[36]. Key NS, Chantrathammachart P, Moody PW, Chang JY. Membrane microparticles in VTE and cancer. Thromb Res. 2010; 125(Suppl 2):S80-3. [PubMed: 20434013] 

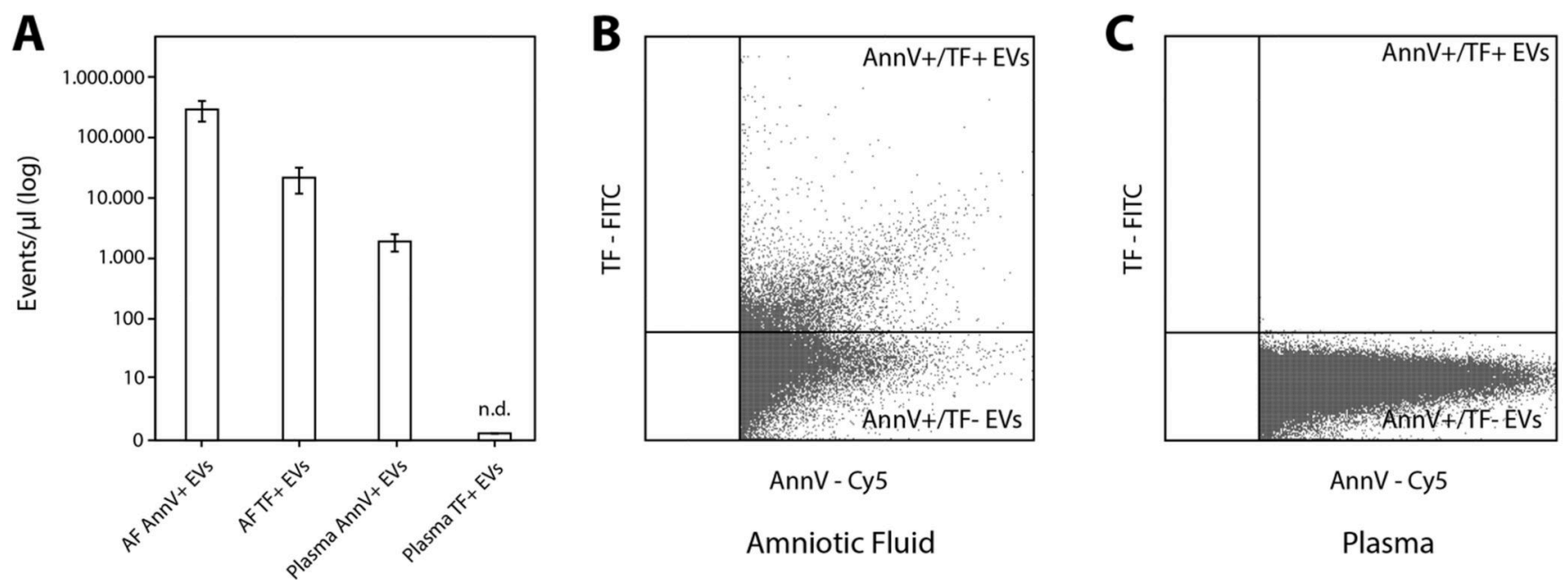

Figure 1. Extracellular vesicles (EVs) quantified by flow cytometry.

(A) $\mathrm{PS}^{+} /$Annexin $\mathrm{V}^{+}$EVs were significantly higher in AF samples $(\mathrm{n}=10)$ compared to plasma samples from healthy controls $(n=7)$ (A and B). In AF a high proportion of detected $\mathrm{PS}^{+}$EVs also exposed TF (A and $\mathbf{C}$ ). In the plasma of healthy controls no $\mathrm{TF}^{+} \mathrm{EVs}$ were detectable. Single measurements were performed. AF, amniotic fluid; PS, phosphatidylserine; TF, tissue factor. 
A

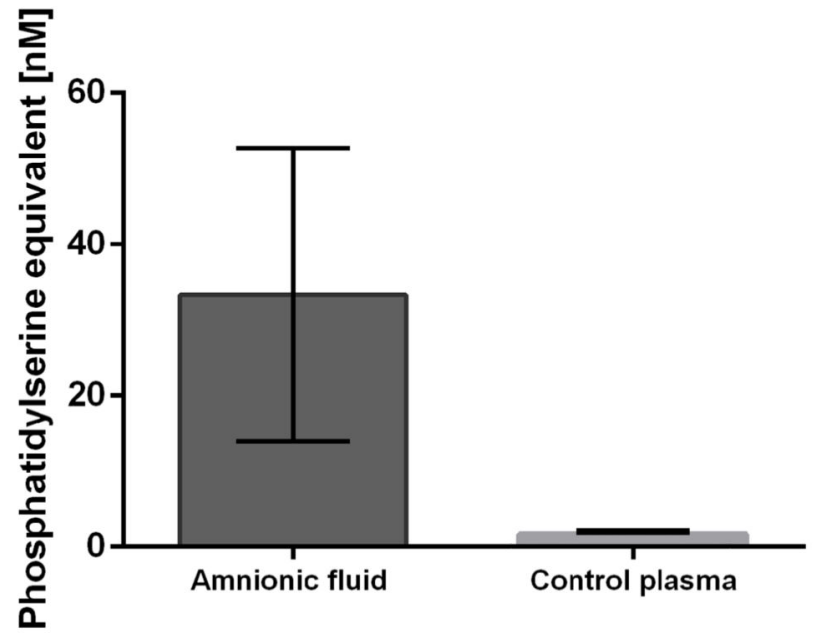

B

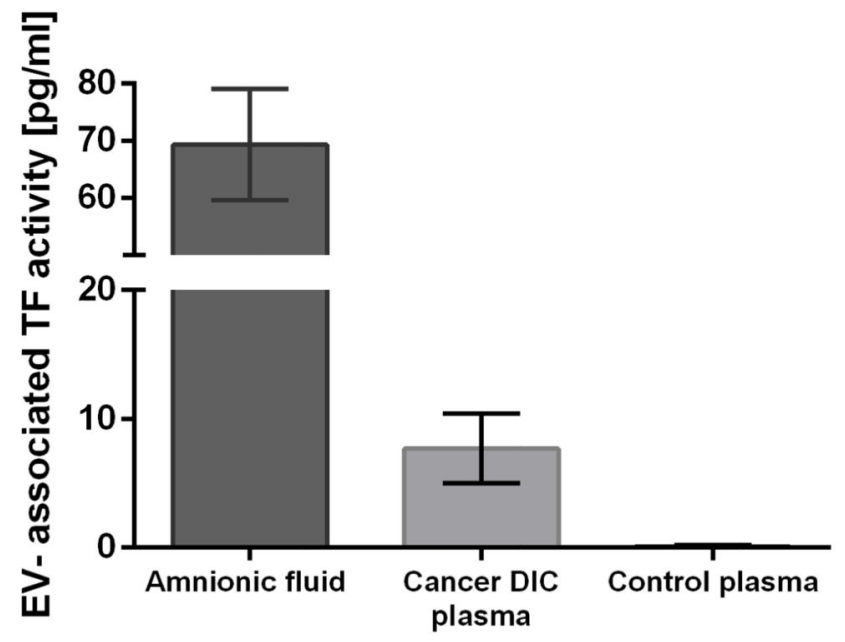

Figure 2. Procoagulant EVs quantified by a functional prothrombinase- and a EV-associated TF activity assay.

(A) PS exposure on EVs determined with a prothrombinase assay was significantly higher in AF $(n=10)$ compared with plasma from healthy controls $(n=7)$. (B) EV-TF activity determined with a factor Xa generation assay was significantly higher in $\mathrm{AF}(\mathrm{n}=10)$ compared with plasma from cancer patients with overt DIC $(n=10)$. EV-TF activity was not detectable in plasma from healthy controls $(n=7)$. Measurements were performed in duplicates. EV, extracellular vesicles; TF, tissue factor; PS, phosphatidylserine; AF, amniotic fluid; DIC, disseminated intravascular coagulation. 


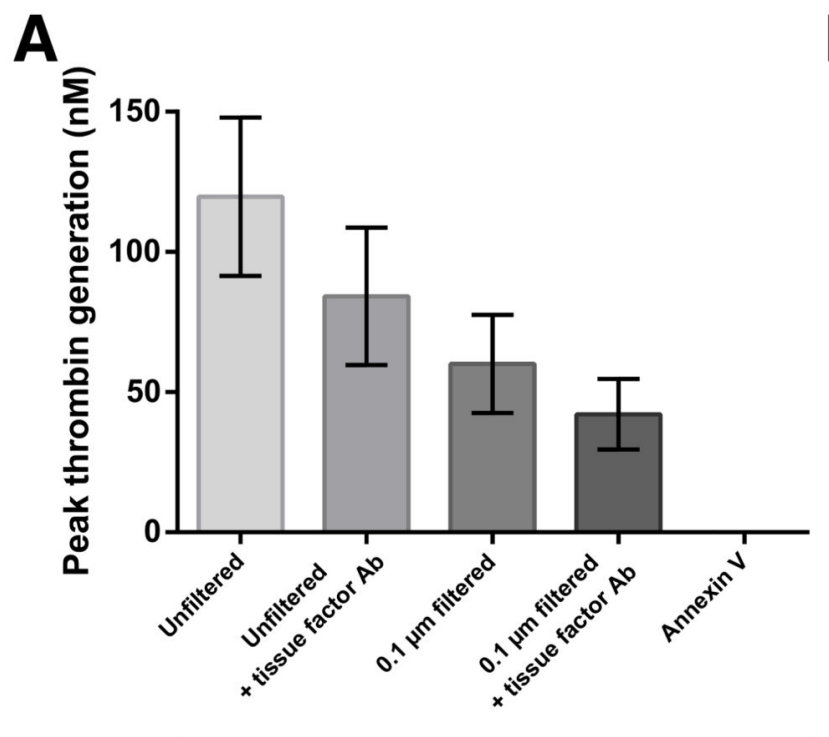

Amnionic fluid

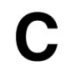

B

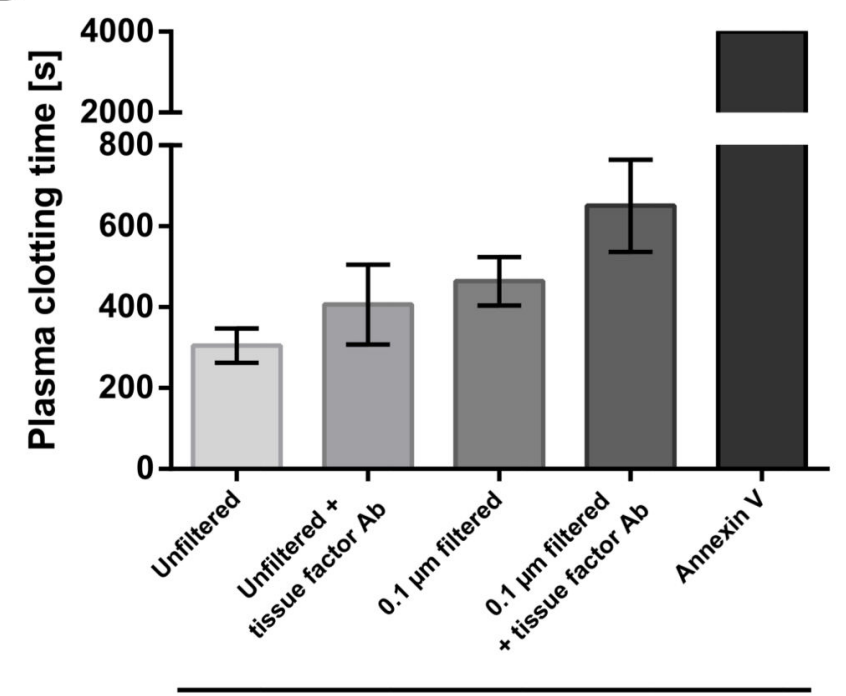

Amnionic fluid

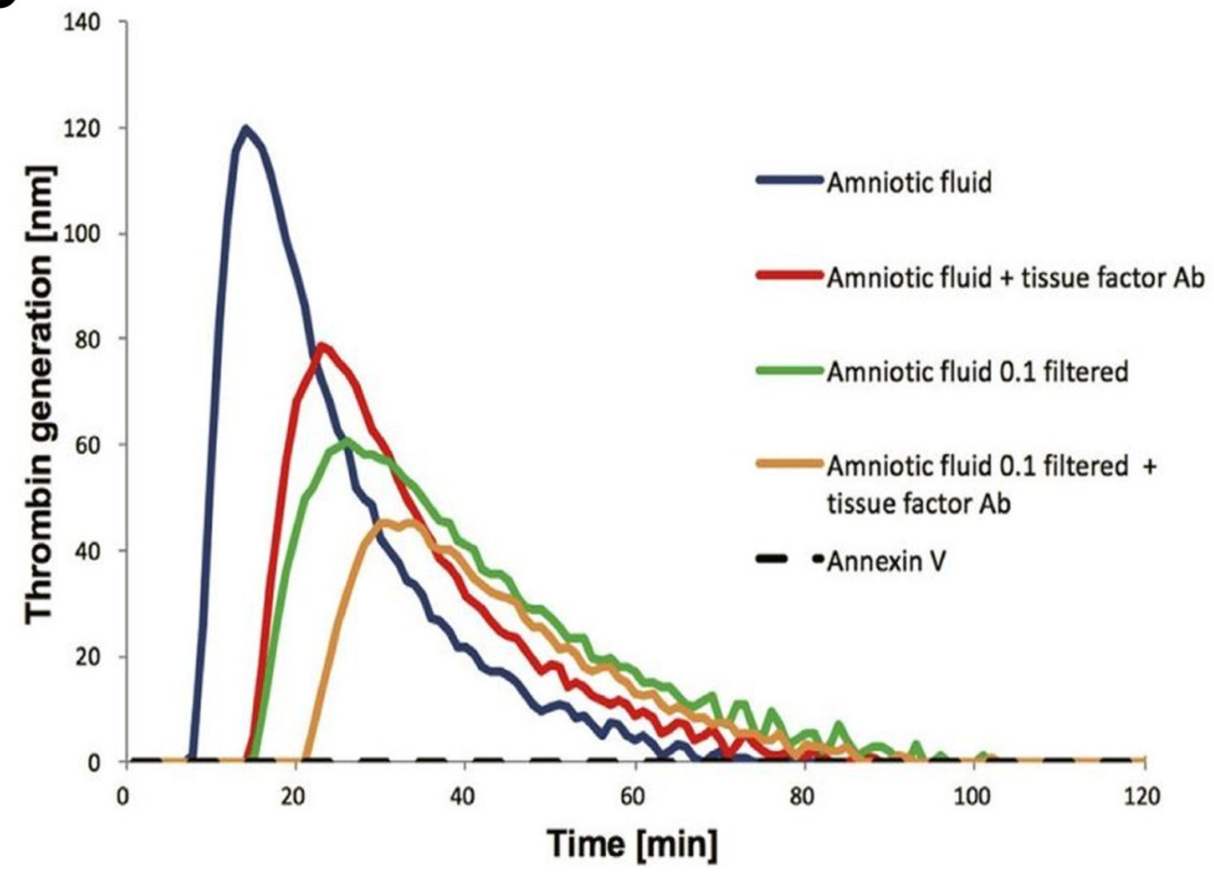

Figure 3. Effect of AF on thrombin- and fibrin generation.

(A) Peak thrombin generation and (B) fibrin clot formation lag phase in vesicle free normal pooled plasma after addition of AF $(n=10)$ with/without anti-TF antibody or annexin $\mathrm{V}$ and/or filtering through a $0.1 \mu \mathrm{m}$ membrane for depletion of larger EVs. Measurements were performed in duplicates. (C) Representative thrombin generation curves. AF, amniotic fluid; $\mathrm{TF}$, tissue factor; EV, extracellular vesicles. 


\section{A}

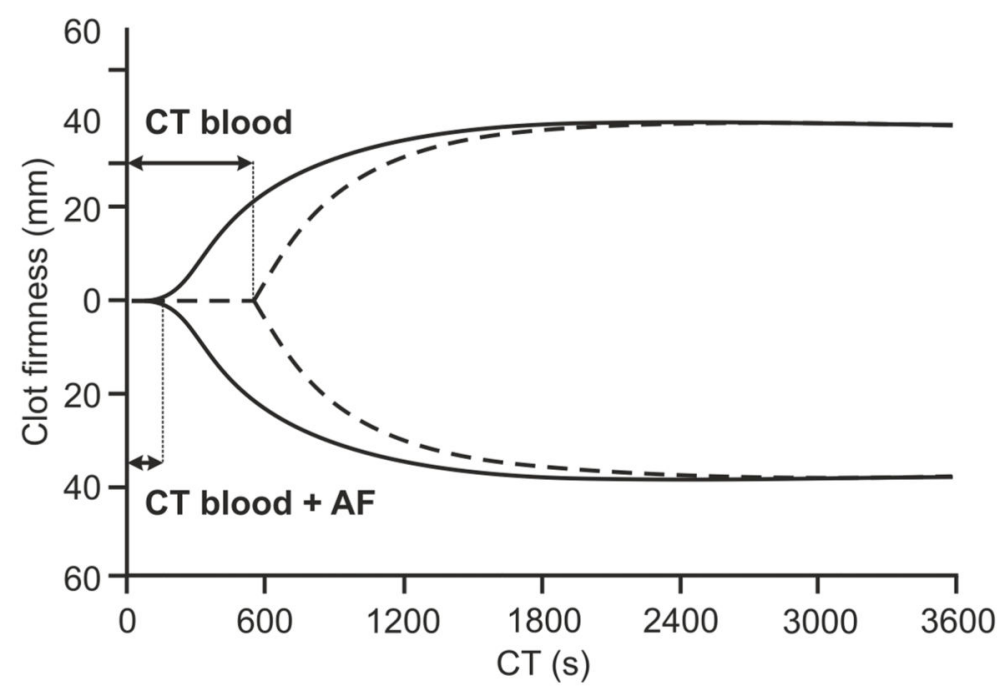

B

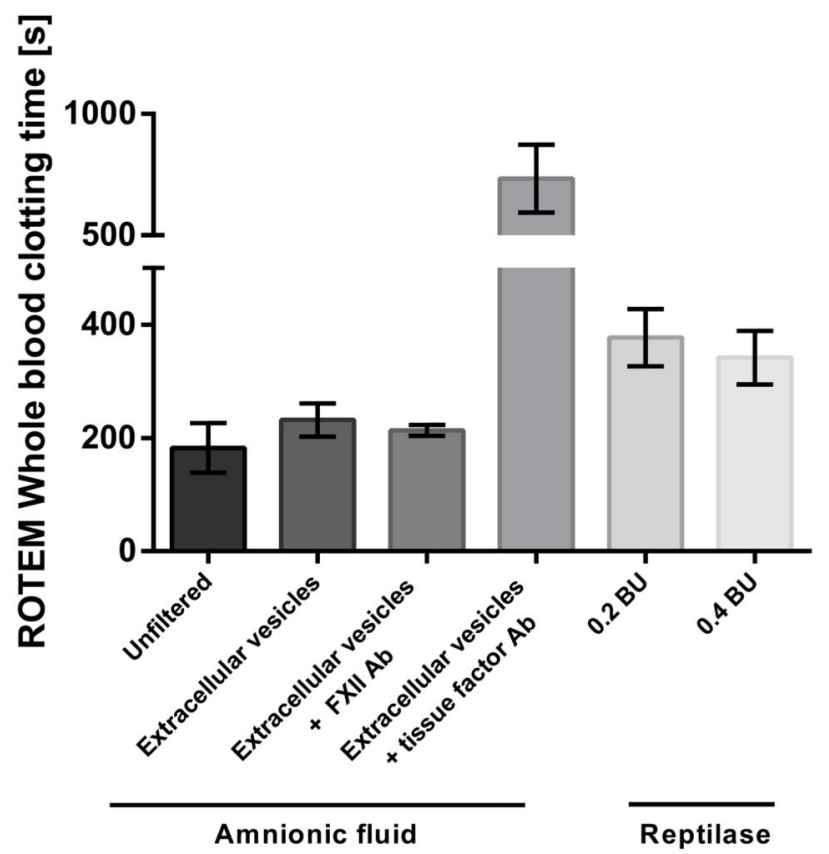

Figure 4. Effect of AF and AF-derived EVs on whole blood clotting monitored by thrombelastrography

(A) Strongly shortened clotting time (CT) of whole blood incubated with AF (solid line) compared to whole blood that was just recalcified (dotted line). (B) Amniotic fluid and amniotic fluid-derived extracellular vesicles shortened the clotting time of whole blood $(n=3)$ more strongly than reptilase, a snake venom that directly converts fibrinogen into fibrin. The procoagulant properties of amniotic fluid depended on tissue factor but not on factor XII. AF, amniotic fluid; EV, extracellular vesicles. 
Table 1

Pearson correlation coefficients of selected parameters of the applied assays

\begin{tabular}{|c|c|c|c|c|c|}
\hline & $\begin{array}{l}\text { EV-associated } \\
\text { prothrombinase } \\
\text { activity }(\mathbf{n M})\end{array}$ & $\begin{array}{l}\text { EV-associated } \\
\text { TF activity } \\
\text { (pg/mL) }\end{array}$ & $\begin{array}{l}\text { Thrombin } \\
\text { generation, } \\
\text { peak }(\mathrm{nM})\end{array}$ & $\begin{array}{l}\text { Thrombin } \\
\text { generation, lag } \\
\text { phase (sec) }\end{array}$ & $\begin{array}{l}\text { Fibrin } \\
\text { generation, lag } \\
\text { phase (sec) }\end{array}$ \\
\hline $\begin{array}{l}\text { EV-associated prothrombinase } \\
\text { activity (nM) }\end{array}$ & & 0.209 & $0.804 *$ & -0.626 & $-0.692 *$ \\
\hline $\begin{array}{l}\text { EV-associated TF activity } \\
(\mathrm{pg} / \mathrm{mL})\end{array}$ & 0.209 & & 0.339 & -0.358 & -0.296 \\
\hline Thrombin generation, peak (nM) & $0.804 *$ & 0.339 & & $-0.750^{*}$ & $-0.790 *$ \\
\hline $\begin{array}{l}\text { Thrombin generation, lag phase } \\
\text { (sec) }\end{array}$ & -0.626 & -0.358 & $-0.750 *$ & & $0.875^{*}$ \\
\hline Fibrin generation, lag phase (sec) & $-0.692 *$ & -0.296 & $-0.790 *$ & $0.875^{*}$ & \\
\hline $\begin{array}{l}\text { Flow cytometry, } \mathrm{PS}^{+} / \mathrm{TF}^{+} \mathrm{EV} \\
\text { count }\end{array}$ & -0.455 & -0.655 & -0.620 & 0.656 & $0.720^{*}$ \\
\hline
\end{tabular}

Abbreviations: EV, extracellular veslicle; PS, phosphatidylserine; TF, tissue factor; sec, seconds. Asterisks indicate statistical significance. 